\title{
Risks and Benefits Associated With Anti- biotic Use for Acute Respiratory Infections: A Cohort Study
}

\author{
Sharon B. Meropol, MD, $\mathrm{PhD}^{1-3}$ \\ A. Russell Localio, $P b D^{3-5}$ \\ Joshua P. Metlay, MD, $P b D^{3-6}$ \\ 'Department of Pediatrics, Case Western \\ Reserve University School of Medicine, \\ Cleveland, Ohio \\ ${ }^{2}$ Department of Epidemiology and Biosta- \\ stics, Case Western Reserve University \\ School of Medicine, Cleveland, Ohio \\ ${ }^{3}$ Penn Center for Education and Research \\ on Therapeutics, University of Pennsyl- \\ vania School of Medicine, Philadelphia, \\ Pennsylvania
}

${ }^{4}$ Center for Clinical Epidemiology and Biostatistics, University of Pennsylvania School of Medicine, Philadelphia, Pennsylvania

${ }^{5}$ Department of Biostatistics and Epidemiology, University of Pennsylvania School of Medicine, Philadelphia, Pennsylvania

${ }^{6}$ Department of Medicine, University of Pennsylvania School of Medicine, Philadelphia, Pennsylvania

Conflicts of interest: authors report none.

\section{CORRESPONDING AUTHOR}

Sharon B. Meropol, MD, PhD

Rainbow Babies and Children's Hospital

11100 Euclid Ave, Mailstop 6054

Cleveland, $\mathrm{OH} 44106$

sharon.meropol@case.edu

\begin{abstract}
PURPOSE Antibiotics are frequently prescribed for acute nonspecific respiratory infections (ARIs), presumably to avoid small risks of progression to serious bacterial illness. However, even low risks of associated adverse drug events could result in many such events at the population level. Our objective was to assess the risks and benefits of antibiotic use in a cohort of patients with ARIs, comparing outcomes of patients who were prescribed antibiotics with outcomes of patients not receiving antibiotics.
\end{abstract}

METHODS We used a June 1986 to August 2006 cohort of adult patients with ARI visits from a UK primary care database. Exposure was an antibiotic prescribed with the visit. Primary outcomes were hospitalization within 15 days for (1) severe adverse drug events (hypersensitivity, diarrhea, seizure, arrhythmia, hepatic or renal failure), and (2) community-acquired pneumonia.

RESULTS The cohort included 1,531,019 visits with an ARI diagnosis; prescriptions for antibiotics were given in $65 \%$ of cases. The adjusted risk difference for treated vs untreated patients per 100,000 visits was 1.07 fewer adverse events $(95 \% \mathrm{Cl},-4.52$ to $2.38 ; P=.54)$ and 8.16 fewer pneumonia hospitalizations (95\% Cl, -13.24 to $-3.08 ; P=.002)$. The number needed to treat to prevent 1 hospitalization for pneumonia was 12,255.

CONCLUSIONS Compared with patients with ARI who were not treated with antibiotics, patients who were treated with antibiotics were not at increased risk of severe adverse drug events and had a small decreased risk of pneumonia hospitalization. This small benefit from antibiotics for a common ambulatory diagnosis creates persistent tension; at the societal level, physicians are compelled to reduce antibiotic prescribing, thus minimizing future resistance, whereas at the encounter level, they are compelled to optimize the benefit-risk balance for that patient.

Ann Fam Med 2013;11:165-172. doi:10.1370/afm.1449.

\section{INTRODUCTION}

$\mathrm{O}$ $\mathrm{n}$ average, every individual in the United States and Europe is prescribed oral antibiotics once every 6 months to 3 years. ${ }^{1-8}$ It is doubtful that we have such a high exposure to any other prescription drug class. ${ }^{9}$ Not surprisingly, antibiotics are among the most common drugs implicated in adverse drug events, ${ }^{10-13}$ mostly through case reports without an unexposed control group. ${ }^{14}$

Acute nonspecific respiratory infections (ARIs) account for more than 2 million UK and 46 million US adult outpatient visits annually. ${ }^{5,15-17}$ Unlike acute localized infections of primarily bacterial cause (eg, bacterial sinusitis, streptococcal pharyngitis), ${ }_{1}^{18-20}$ studies have failed to show a clear benefit from antibiotics for these conditions (eg, acute nasopharyngitis, acute bronchitis). ${ }^{21,22}$ Many of these studies were relatively small and potentially underpowered to detect small but clinically significant ben- 
efits, ${ }^{21,23-25}$ which could include faster disease resolution or prevention of progression to more serious bacterial infections, such as community-acquired pneumonia. Given the high incidence of ARI, even a small relative benefit might translate into a large public health effect.

Numerous practice guidelines ${ }^{23,26-29}$ recommend against antibiotic treatment for ARIs, but about onehalf of US and UK adults with ARI diagnoses receive antibiotic prescriptions. ${ }^{4,5,17,22}$ Many clinicians and their patients must believe that the potential benefits of antibiotics outweigh the risks for ARIs, but the true risks of benefit and harm from antibiotic treatment vs no treatment remain unknown within this context. Although randomized clinical trials can set an upper limit on the magnitude of benefits and harms, randomized trials large enough to quantify these rare outcomes are impractical. An alternative strategy is to compare risks and benefits in situations in which antibiotic prescribing decisions are based, at least partially, on nonclinical factors, such as patient expectation or physician practice patterns.

Our objective was to use outpatient ARI visits to estimate the risks of both subsequent serious adverse drug events and community-acquired pneumonia, comparing antibiotic-exposed with unexposed patients. By limiting the assessment to patients with similar conditions, we promoted comparability between exposed and unexposed patients. Our hypotheses were that patients treated with antibiotics have a small, but measurable, increased risk of a serious adverse event and a decreased risk of hospitalization for pneumonia when compared with untreated patients.

\section{METHODS}

This retrospective cohort study used data from the UK's The Health Improvement Network (THIN, owned by CSD Medical Research UK), a large primary care electronic medical record database with longitudinal prescription and outcome data. ${ }^{30-33}$ Data are reviewed on an ongoing basis for quality and completeness. ${ }^{30,34-36}$ We accessed THIN data from practices meeting acceptable standards for research data collection as of September 2007. We identified all primary care visits with Read diagnostic codes for ARIs (a coding system similar to International Classification of Diseases codes; Supplemental Appendix, Table A1, available at

http://annfammed.org/content/11/2/165/suppl/

A DC1) between January 1, 1985, and December

31, 2006, among permanently registered continuously enrolled adults (18 years and older). We excluded codes for diagnoses often attributed to a bacterial origin for which guidelines recommend antibiotics (eg, community-acquired pneumonia, acute exacerbations of chronic bronchitis) ${ }^{18-20}$ Because data from multiple visits within the same illness episode may be highly correlated, visits were grouped if they occurred within a 2-week period.

The exposure of interest was an oral antibiotic prescription within 1 day of the ARI visit, including drugs typically used for respiratory tract infections. We excluded drugs used for tuberculosis and for fungal and parasitic infections. Any antibiotic prescription within an illness episode of grouped visits counted as a single exposure. The primary window during which we considered the patient to be antibiotic exposed was within 15 days after the visit, regardless of prescription duration. ${ }^{37}$

Hospital admissions were identified using the THIN source flags suggested by CSD Medical Research UK to detect overnight hospital admissions. The primary outcome was a severe adverse event within 15 days after the index visit, defined as overnight hospitalization with 1 of the following diagnoses: cardiac arrhythmia, diarrhea, hepatic toxicity, hypersensitivity, phototoxicity, renal toxicity, or seizure $^{37}$ (Supplemental Appendix, Table A2). The primary pneumonia outcome was hospitalization for pneumonia within 15 days following the ARI visit, defined using diagnostic codes for community-acquired pneumonia (Supplemental Appendix, Table A3). In previous work, we showed that these THIN pneumonia and hospital admission codes have excellent positive predictive value for identifying valid overnight hospitalizations for community-acquired pneumonia ${ }^{38}$ and their dates. ${ }^{38,39}$ As a secondary outcome, we analyzed less serious adverse events, defined as ambulatory care visits for the same adverse event diagnoses within 14 days, but not associated with hospitalization.

Exploratory analyses included modeling specific antibiotic drug class exposures, focusing on $\beta$-lactams, macrolides, and fluoroquinolones, as class-specific antibiotic vs no antibiotic exposure (and as class-specific vs other antibiotic, reported in the Supplemental Appendix). Of particular interest were drugs suspected of increasing the risk of cardiac arrhythmias and drugs metabolized via the hepatic CYP3A4 pathway; macrolides and fluoroquinolones are frequently implicated in adverse events through these mechanisms. ${ }^{40-42} \mathrm{We}$ did not have adequate power to model each individual adverse event category separately. ${ }^{43,44}$

Covariates included visit age, sex, visit year, and summary measures of medical care intensity, including the number of recorded comorbidities, ${ }^{11}$ the number of different classes of medications prescribed ${ }_{1}^{11,45}$ and the number of THIN visits for that patient within the year before the index visit. THIN does not include direct measures of patients' socioeconomic, racial, and eth- 
nic characteristics; the Townsend score, ${ }^{46}$ a 5 -quintile measure of neighborhood deprivation, and a 5-quintile variable describing the racial composition of the patient's neighborhood were used as proxies of these characteristics.

\section{Analysis}

We first described the frequency of ARI visits and antibiotic exposure, overall and by specific British National Formulary class, ${ }^{47}$ and identified adverse events and pneumonia hospitalizations for our cohort.

For our primary multivariable analyses, we modeled our outcomes (hospital admission for any severe adverse event, and hospital admission for pneumonia) on any vs no antibiotic exposure. We used fixed-effects conditional linear regression with practice as a grouping variable, which enabled us to use data from practices with zero outcomes, adjust for between-practice imbalance of antibiotic prescribing and/or outcomes, and obtain practice-specific estimates. Simulations confirmed that this regression model provided reliable estimates for our rare outcome (details in the Supplemental Appendix). We retained a covariate in the final model when it was independently associated with the outcome and if removing it caused a change of $10 \%$ or greater in the risk difference. We used the Akaike information criterion to help assess model fit ${ }^{48}$ and the Cuzick nonparametric test for trend across ordered groups. ${ }^{49}$ Stata 10.0 (StataCorp LP) was used for all analyses.

We conducted a series of sensitivity analyses. First, for both adverse events and pneumonia outcomes, we extended the exposure window to 30 days to address

\section{Figure 1. Area plot of frequency of antibiotic prescribing for acute nonspecific respiratory infections for each of 326 practices, by practice.}

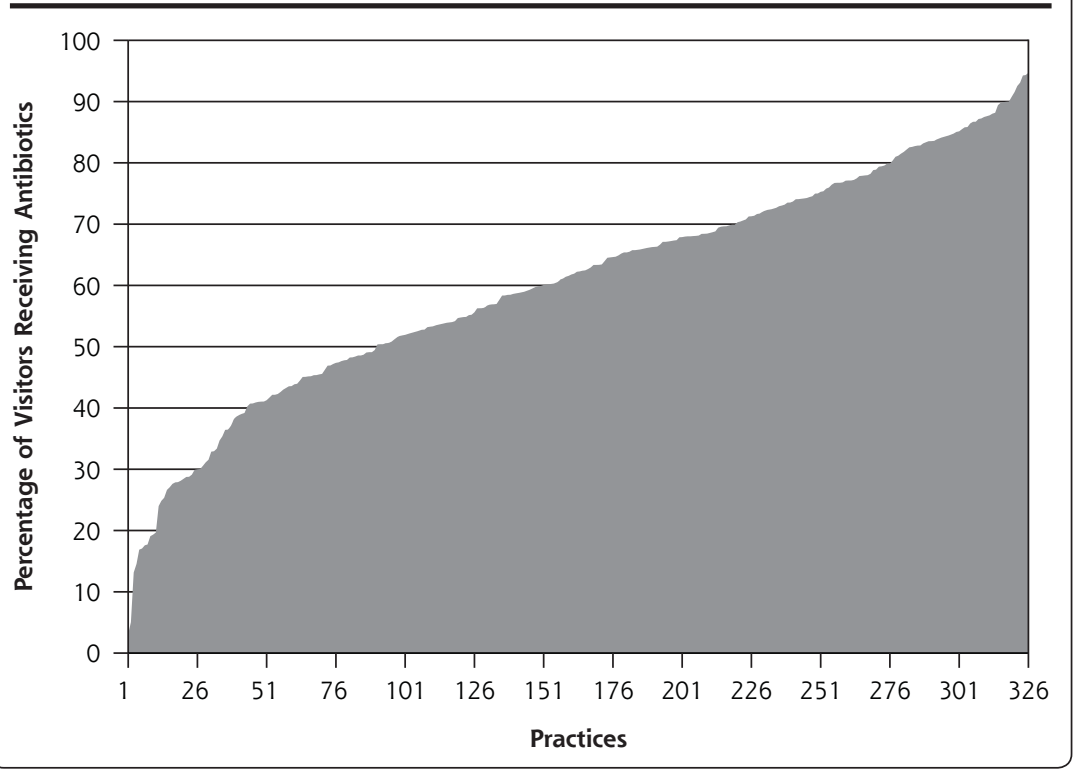

potential misclassification of admission dates. For pneumonia, considering that hospitalization occurring within 1 day of the ARI visit may be more related to the patient's original diagnosis than to the physician's antibiotic treatment decision, we also modeled admission between 2 to 15 days after the visit, eliminating relatively immediate hospital admissions. We also explored the possibility that visits coded as acute bronchitis might behave differently than visits with other ARI diagnoses, modeling pneumonia hospitalization outcomes in 2 additional ways: first we eliminated visits with a bronchitis diagnosis, and second, we included only visits with a bronchitis diagnosis.

We performed additional analyses to confirm our methodologic assumptions (detailed in the Supplemental Appendix). Results using ungrouped visits and propensity scores were similar to the primary analysis. We modeled a control outcome (hospitalizations for motor vehicle accidents) and obtained the expected outcome of no association between antibiotic treatment and accident hospitalization. To explore the possible influence of unmeasured confounders for patients with severe adverse events and multiple visits within the cohort, we performed a crossover-cohort study, comparing antibiotic treatment for each patient's adverse event visit vs for all of their previous visits; results were qualitatively similar to the primary analysis.

This study was approved by the University of Pennsylvania Institutional Review Board and the Medical Research Ethics Committee, National Research Ethics Service, UK National Health Service.

\section{RESULTS}

Our cohort contained 1,646,229 total and 1,531,019 grouped visits for ARIs by 814,283 patients. There were 326 practices represented, and the mean number of visits per practice was 4,696 (range, 24 to 27,190$) ; 361,553$ visits were for bronchitis diagnoses.

\section{Antibiotic Exposure}

Antibiotics were prescribed for $65 \%$ of ARI visits. Antibiotic prescribing varied widely among practices, ranging from $3 \%$ to $95 \%$ of visits (Figure 1). The most frequent antibiotic prescribed was amoxicillin, followed by penicillin and erythromycin, accounting for $51.2 \%, 17.0 \%$, and $12.7 \%$ of prescriptions, respectively (Table 1 ). 


\section{Table 1. Antibiotics Prescribed}

\begin{tabular}{lc}
\hline Generic Name & No. of Visits \\
\hline Penicillins & 685,265 \\
Macrolides & 126,934 \\
Cephalosporins, cephamycins, & 71,646 \\
and other $\beta$-lactams & 70,554 \\
Tetracyclines & 34,629 \\
Sulphonamides and trimethoprim & 12,203 \\
Quinolones & 819 \\
Other & $1,002,050$ \\
Total visits with antibiotics & \\
\hline a Metronidazole, methenamine, nitrofuratoin, fosfomycin, amoxicillin/clarithro- \\
mycin/lansoprazole, clindamycin, colistin, chloramphenicol, and fusidic acid.
\end{tabular}

Patients receiving antibiotics were older, had more comorbidities, and were prescribed more drug classes within the previous year. The number of primary care visits within the previous year was similar for treated compared with untreated patients, however (Table 2).

\section{Severe Adverse Events}

There were 126 severe adverse events within the cohort. The crude incidence rate of events within 15 days was 8.22 events per 100,000 ARI visits; 8.48 events per 100,000 visits with antibiotic treatment, and 7.75 events per 100,000 visits without treatment (Table 3 ).

Adjusting for clustering by practice, the unadjusted estimate for the risk difference for a severe adverse event for patients treated vs not treated with antibiotics was 0.37 fewer events per 100,000 patient visits $(95 \% \mathrm{CI},-5.31$ to 2.07 ). Adjusting for age, study year, drugs, and visits over the preceding year, and Townsend score, the risk difference was 1.07 fewer severe adverse events per 100,000 patient visits $(95 \% \mathrm{CI},-4.52$ to $2.38 ; P=.54)$ comparing antibiotictreated vs untreated patients (Table 4 ).

By extending the exposure window to 30 days from the ARI visit, we found a greater risk reduction for antibiotic exposed vs unexposed patients, although still not statistically significant, with a risk difference of 3.79 fewer adverse events per 100,000 patient visits $(95 \% \mathrm{CI},-8.38$ to 0.80 ; $P=.11)$. When assessing classspecific antibiotic exposure vs no exposure, although point estimates varied, we found that none was statistically significant (Table 4).

We also examined minor adverse events, defined as the same diagnostic codes evaluated at a primary care visit that did not result in hospitalization. The unadjusted risk difference was 111.98 more minor adverse events per 100,000 patient visits for antibiotic-treated vs antibiotic-untreated patients; after multivariable adjustment, the risk difference was 55.58 more minor adverse events per 100,000 patient visits $(95 \% \mathrm{CI}$, 28.00 to $83.18 ; P<.001)$.

\section{Community-Acquired Pneumonia}

There were 296 hospital admissions for pneumonia within 15 days of the index visit: 180 patients treated with antibiotics, and 116 patients without antibiotics. The unadjusted mean incidence rate of hospitalization for pneumonia was 19.33 per 100,000 visits; 21.93 without antibiotic treatment, and 17.96 with treatment, giving a crude risk difference of 3.97 fewer hospital admissions per 100,000 visits for antibiotic-treated patients.

Using the regression model, the unadjusted withinpractice risk difference was a protective effect of antibiotic use of 4.53 fewer admissions for pneumonia per 100,000 visits for antibiotic treated vs untreated patients. The final model adjusted for age, year, num-

\begin{tabular}{|c|c|c|}
\hline Characteristic & $\begin{array}{l}\text { Visits With } \\
\text { Antibiotics }\end{array}$ & $\begin{array}{l}\text { Visits Without } \\
\text { Antibiotics }\end{array}$ \\
\hline Total visits ( $N=1,531,019)$, No. (\%) & $1,002,050(65.4)$ & $528,969(34.6)$ \\
\hline Male, No. (\%) & $385,712(38.5)$ & $184,720(35)$ \\
\hline Age, median (mean) y & 46 (47.91) & $40(43.98)$ \\
\hline \multicolumn{3}{|l|}{ Comorbidities } \\
\hline Any comorbidity, No. (\%) & $350,078(34.94)$ & $161,607(30.55)$ \\
\hline Number of comorbidities, mean & 0.48 & 0.41 \\
\hline $\begin{array}{l}\text { Number of different classes of drugs } \\
\text { used in previous year, mean }\end{array}$ & 5.98 & 4.25 \\
\hline $\begin{array}{l}\text { Number of visits made in previous } \\
\text { year, mean }\end{array}$ & 8.94 & 8.87 \\
\hline
\end{tabular}

\begin{tabular}{|c|c|c|c|c|c|c|}
\hline \multirow[b]{2}{*}{$\begin{array}{l}\text { Time After } \\
\text { Index Visit }\end{array}$} & \multicolumn{2}{|c|}{$\begin{array}{l}\text { With Antibiotics } \\
1,002,050 \text { Visits }\end{array}$} & \multicolumn{2}{|c|}{$\begin{array}{c}\text { Without Antibiotics } \\
528,969 \text { Visits }\end{array}$} & \multirow[b]{2}{*}{$\begin{array}{c}\text { Risk } \\
\text { Difference }^{a}\end{array}$} & \multirow[b]{2}{*}{$\begin{array}{c}P \\
\text { Value }\end{array}$} \\
\hline & $\begin{array}{l}\text { No. of } \\
\text { Events }\end{array}$ & $\begin{array}{l}\text { Event } \\
\text { Rate }^{a}\end{array}$ & $\begin{array}{l}\text { No. of } \\
\text { Events }\end{array}$ & $\begin{array}{l}\text { Event } \\
\text { Rate }^{a}\end{array}$ & & \\
\hline 15 days & 85 & 8.48 & 41 & 7.75 & 0.73 & .63 \\
\hline 30 days & 148 & 14.77 & 80 & 15.12 & -0.35 & .86 \\
\hline \multicolumn{7}{|c|}{$\begin{array}{l}\text { Note: The following events occurred at } 15 \text { days: hypersensitivity } 44 \text {, diarrhea } 18 \text {, liver toxicity } 13 \text {, renal toxic- } \\
\text { ity } 21 \text {, arrhythmia } 6 \text {, seizure } 23 \text {; at } 30 \text { days, hypersensitivity } 79 \text {, diarrhea } 25 \text {, liver toxicity } 28 \text {, renal toxicity } 39 \text {, } \\
\text { arrhythmia } 11 \text {, seizure } 46 \text {. } \\
\text { a Per } 100,000 \text { visits. }\end{array}$} \\
\hline
\end{tabular}




\section{Table 4. Severe Adverse Events Per 100,000 Visits by Antibiotic Class}

\begin{tabular}{lccc}
\hline \multirow{2}{*}{ Grouped Visits } & \multicolumn{3}{c}{ Risk Difference for Antibiotic Use } \\
\cline { 2 - 4 } & Point Estimate & $95 \% \mathrm{Cl}$ & P Value \\
\hline All antibiotic use vs none & -1.07 & -4.52 to 2.38 & .54 \\
Specific antibiotic class vs none & & & \\
$\beta$-Lactams & -1.62 & -5.19 to 1.96 & .37 \\
Macrolides & 2.40 & -3.26 to 8.07 & .40 \\
Flouroquinolones & 1.06 & -17.02 to 19.14 & .91 \\
\hline
\end{tabular}

There was an apparent increased risk of 55.58 more minor adverse events requiring outpatient follow-up per 100,000 patient visits with antibiotic exposure. Although not life threatening, milder events can be clinically important in terms of unpleasant symptoms, medical needs, and missed work days. Minor adverse events after antibiotic treatment might be more likely to be reported and recorded than similar events without treatment, however. In contrast, adverse ber of comorbidities, and number of drugs: there was a risk difference of 8.16 fewer hospital admissions per 100,000 visits $(95 \% \mathrm{CI},-13.24$ to $-3.08, P=.002)$, comparing antibiotic-treated with untreated patients. This risk difference corresponds to a number needed to treat of 12,255 patients to prevent 1 hospital admission.

When the window of interest was extended to 30 days, adjusting for the same covariates, the risk difference was 9.35 fewer hospitalizations per 100,000 visits (95\% CI, -15.22 to $-3.47 ; P=.002)$. Excluding admissions within 1 day of the index visit yielded a risk difference of 4.38 fewer pneumonia hospitalizations per 100,000 visits $(95 \% \mathrm{CI},-9.08$ to $0.331 ; P=.068)$. Eliminating the 361,553 patients with a diagnosis of acute bronchitis, the risk difference was 9.01 fewer hospitalizations per 100,000 visits $(95 \% \mathrm{CI},-13.43$ to $-4.58 ; \mathrm{P}$ $<.001$ ). Conversely, analyzing only the 361,553 acute bronchitis visits, the risk difference for pneumonia hospitalization was 37.26 fewer per 100,000 visits (95\% $\mathrm{CI},-59.71$ to $-14.81 ; P=.001)$.

\section{DISCUSSION}

Decisions regarding antibiotic prescribing are made at the level of each individual physician-patient relationship, where patient-level risk/benefit considerations and preference are likely to take precedence over societal considerations. ${ }^{50}$ Quantifying individual-level risks is not always straightforward. Antibiotic use is so common that patients can sometimes experience outcomes that appear temporally related to medication use, even if no causal relationship exists. We compared specific hospital admission outcomes for antibiotic-treated vs untreated patients evaluated in the primary care setting for an ARI.

Patients with ARIs treated with antibiotics were not at increased risk of severe adverse events, with a point estimate of 1.07 fewer adverse events per 100,000 visits and a confidence interval that included zero. None of the antibiotic classes were shown to definitively increase the severe adverse event risk. events that result in hospitalization are less likely to be subject to information bias; patients who experience these more serious events are likely to seek medical care, and the indication for hospitalization is likely to be documented regardless of whether the patient was on antibiotic treatment. ${ }^{38}$

We found that the overall risk of hospitalization for community-acquired pneumonia after an ARI visit, comparing antibiotic-treated vs untreated patients, was 8.16 fewer per 100,000 visits; the number needed to treat was 12,255 patients to prevent 1 hospitalization. The risk difference was attenuated toward the null when not considering hospitalizations during the first day after the ARI visit. It is possible that antibiotics may have their greatest effect on the acute exacerbation of a rapidly evolving bacterial illness or that some of the benefit of antibiotics can be attributed to misdiagnosing patients with community-acquired pneumonia as having other nonbacterial acute respiratory infections at the initial visit.

Ecologic studies have shown that concurrent with decreasing UK and US antibiotic prescribing rates from 1996 to 2003, hospital admissions increased for respiratory tract infections. ${ }^{51,52}$ Petersen et al used the UK primary care General Practice Research Database to look at subsequent visits with a diagnosis of pneumonia after outpatient treatment for "upper respiratory tract infection" and "chest infection." ${ }^{153}$ They found an odds ratio for chest infection in the month after a visit for upper respiratory tract infection of 0.64 for patients treated vs untreated with antibiotics; their risk of pneumonia within 1 month of chest infection was high and reduced by initial antibiotic treatment, with odds ratios comparing antibiotic treated with untreated patients ranging from 0.22 to 0.35 , depending on patient age. As the authors point out, however, chest radiography is not often available in primary care, and the "chest infection" codes used to define their cohort could have included patients with both acute bronchitis and patients with the outcome, pneumonia; furthermore, hospitalization status was not specified, so it is difficult to directly compare their results to those of our study. 
We were limited by the potential inaccuracy of THIN data. Prescriptions are generated by medical record data entry, so drug information capture in THIN is virtually $100 \%{ }^{54,55}$; however, we have no data regarding whether antibiotic prescriptions were filled or ingested. We previously found that pneumonia and hospital admission codes had good specificity for identifying hospitalizations for pneumonia in this database. ${ }^{38}$ Even so, outcomes may be more likely to be identified and diagnosed as such for patients who are hospitalized; admissions not related to antibiotic treatment would have tended to bias our results toward the null. Had decisions to admit for adverse events or pneumonia been different depending on whether patients had been previously prescribed antibiotics, however, our results could have been biased away from the null.

A limitation of our observational study is that antibiotic exposure was not randomized, and there may be systematic differences in the indication for antibiotics between those who received them and those who did not. Indeed, patients who received antibiotics were older and did appear sicker according to some indicators. Although we could not address all potential confounders, adjusting for those patient characteristics available in THIN did not change our primary result; if anything, it moved away from the null in the direction of fewer adverse events with antibiotics. To the degree that antibiotics are prescribed for sicker patients with ARIs, residual unmeasured confounding would likely have biased us toward finding a positive association between antibiotic exposure and hospitalization, but our result was the opposite.

Perhaps some of the THIN-coded "acute nonspecific respiratory tract infections" were really illnesses with a bacterial focus. For example, if early bacterial pneumonia was misclassified as bronchitis and antibiotic decisions were random, the absence of antibiotic treatment would most likely be associated with failure to improve and an increased risk of hospitalization for pneumonia, which would have biased us in the direction of the results we found. Many of the pneumonia admissions occurred within 1 day of the ARI visit; these very early admissions may be more likely to represent misdiagnosis of bacterial pneumonia as nonspecific ARI. Thus, the secondary outcome eliminating these early hospital admissions may more accurately measure the benefit of antibiotics for preventing the progression of nonspecific ARI to subsequent pneumonia.

Finally, although this study was performed using data from the United Kingdom, they should be generalizable to patients treated with antibiotics for similar illnesses in other countries; there is no reason to expect that individuals in the United Kingdom have different risks related to antibiotic treatment than those living elsewhere. Results from this study are not necessarily generalizable to patients with illnesses other than ARIs, with other types of outcomes than those measured here, or in different populations, for example, for children.

At the societal level, we are highly interested in eliminating unnecessary antibiotic prescribing to help slow the spread of antibiotic resistance. At the level of the physician-patient encounter, physicians and patients are most interested in providing treatment that will best balance benefits and risks for that particular patient; the apparent best decision at the patient level is not always ideal at the societal level. Although the number needed to treat to prevent 1 pneumonia hospital admission exceeds generally accepted thresholds for preventing serious infections, ${ }^{56-58}$ antibiotic treatment of ARIs is still common ${ }^{5,17}$; the precise value of that boundary can depend on the perspective of the decision maker and, even for the most conscientious of us, may differ between what we may deem ideal for society in general and what we decide for the patient sitting in front of us. ${ }^{50,59}$

This dilemma creates an important challenge. In addition to further practice guidelines and educational efforts aimed at physicians and the public, future research can explore complementary win-win solutions that could serve the interests of society and individual patients together. ${ }^{60}$ Expanded influenza vaccination and novel point-of-service rapid diagnostic techniques ${ }^{61}$ could help target antibiotics to those patients most likely to benefit. Even though these services may be costly, scaling up their use would decrease marginal costs considerably, and from a societal standpoint, if this investment decreases unnecessary antibiotic use, it may be considered cost-effective.

Patients with ARIs treated with antibiotics compared with untreated patients were not at increased risk of subsequent severe adverse events, but they do seem to have a small decreased risk of hospitalization for community-acquired pneumonia with a high number needed to treat to avoid 1 case of pneumonia.

To read or post commentaries in response to this article, see it online at http://www.annfammed.org/content/11/2/165.

Key words: drugs; infectious diseases; pneumonia; outcome assessment (health care); health services research; databases as topic

Submitted December 28, 2011; submitted, revised, June 27, 2012; accepted July 16, 2012.

Funding support: Support for this project was provided by a grant from CSD MR, NIAID grants F32-AI-073015 (SBM) and K24 AI073957 (JPM), NCRR grant UL1-RR02-4134, and grant U18 HS016946 from the Agency for Healthcare Research and Quality.

Disclaimer: The content is solely the responsibility of the authors and 
does not necessarily represent the official views of the Agency for Healthcare Research and Quality.

Previous presentation: This work was presented, in part, at the 26th Annual International Conference on Pharmacoepidemiology $\&$ Therapeutic Risk Management, August 21, 2010, Brighton, United Kingdom.

\section{References}

1. Col NF, O'Connor RW. Estimating worldwide current antibiotic usage: report of Task Force 1. Rev Infect Dis. 1987;9(Suppl 3):S232-S243.

2. Halasa NB, Griffin MR, Zhu Y, Edwards KM. Decreased number of antibiotic prescriptions in office-based settings from 1993 to 1999 in children less than five years of age. Pediatr Infect Dis J. 2002;21 (11):1023-1028.

3. Finkelstein JA, Stille C, Nordin J, et al. Reduction in antibiotic use among US children, 1996-2000. Pediatrics. 2003;112(3 Pt 1):620-627.

4. Roumie CL, Halasa NB, Grijalva CG, et al. Trends in antibiotic prescribing for adults in the United States-1995 to 2002. J Gen Intern Med. 2005;20(8):697-702.

5. Grijalva CG, Nuorti JP, Griffin MR. Antibiotic prescription rates for acute respiratory tract infections in US ambulatory settings. JAMA. 2009;302(7):758-766

6. Halasa NB, Griffin MR, Zhu Y, Edwards KM. Differences in antibiotic prescribing patterns for children younger than five years in the three major outpatient settings. J Pediatr. 2004;144(2):200-205.

7. McCaig LF, Besser RE, Hughes JM. Antimicrobial drug prescription in ambulatory care settings, United States, 1992-2000. Emerg Infect Dis. 2003;9(4):432-437.

8. Goossens H, Ferech M, Vander Stichele R, Elseviers M; ESAC Project Group. Outpatient antibiotic use in Europe and association with resistance: a cross-national database study. Lancet. 2005;365(9459): 579-587.

9. Twenty most frequently mentioned drug names at office visits, by new or continued status: United States, 2008. In: National Ambulatory Medical Care Survey: 2008 Summary Tables. http://www.cdc.gov/ nchs/data/ahcd/namcs_summary/2008_namcs_web_tables.pdf. Accessed Apr 22, 2012

10. Budnitz DS, Shehab N, Kegler SR, Richards CL. Medication use leading to emergency department visits for adverse drug events in older adults. Ann Intern Med. 2007;147(11):755-765.

11. Gandhi TK, Weingart SN, Borus J, et al. Adverse drug events in ambulatory care. N Engl J Med. 2003;348(16):1556-1564.

12. Budnitz DS, Pollock DA, Weidenbach KN, Mendelsohn AB, Schroeder TJ, Annest JL. National surveillance of emergency department visits for outpatient adverse drug events. JAMA. 2006;296(15): 1858-1866.

13. Budnitz DS, Lovegrove MC, Shehab N, Richards CL. Emergency hospitalizations for adverse drug events in older Americans. N Engl J Med. 2011;365(21):2002-2012

14. Hunter D. First, gather the data. N Engl J Med. 2006;354(4):329-331.

15. Office for National Statistics. Census 2001 Key Statistics-Rural and urban area classification 2004 KSO2 Age structure. http://www. ons.gov.uk/ons/rel/census/census-2001-key-statistics/rural-andurban-area-classification-2004/rural-and-urban-area-classification2004-ks02--age-structure.xIs. Accessed Apr 19, 2012.

16. Age Groups and Sex. 2010: 2010 Census Summary File 1. http:// factfinder2.census.gov/faces/tableservices/jsf/pages/productview. xhtml?pid=DEC_10_SF1_QTP1EprodType=table. Accessed Apr 19, 2012.

17. Meropol SB, Chen Z, Metlay JP. Reduced antibiotic prescribing for acute respiratory infections in adults and children. Br J Gen Pract. 2009;59(567):e321-e328.
18. Rosenfeld RM, Andes D, Bhattacharyya N, et al. Clinical practice guideline: adult sinusitis. Otolaryngol Head Neck Surg. 2007;137(3) (Suppl):S1-S31.

19. Choby BA. Diagnosis and treatment of streptococcal pharyngitis. Am Fam Physician. 2009;79(5):383-390.

20. Mandell LA, Wunderink RG, Anzueto A, et al; Infectious Diseases Society of America; American Thoracic Society. Infectious Diseases Society of America/American Thoracic Society consensus guidelines on the management of community-acquired pneumonia in adults. Clin Infect Dis. 2007;44(Suppl 2):S27-S72.

21. Arroll B, Kenealy T. Antibiotics for the common cold and acute purulent rhinitis. Cochrane Database Syst Rev. 2005;(3):CD000247.

22. Gonzales R, Steiner JF, Sande MA. Antibiotic prescribing for adults with colds, upper respiratory tract infections, and bronchitis by ambulatory care physicians. JAMA. 1997;278(11):901-904.

23. Gonzales R, Bartlett JG, Besser RE, et al. Principles of appropriate antibiotic use for treatment of acute respiratory tract infections in adults: background, specific aims, and methods. Ann Intern Med. 2001;134(6):479-486

24. Bucher HC, Tschudi P, Young J, et al; BASINUS (Basel Sinusitis Study) Invetigators. Effect of amoxicillin-clavulanate in clinically diagnosed acute rhinosinusitis: a placebo-controlled, double-blind, randomized trial in general practice. Arch Intern Med. 2003;163(15): 1793-1798.

25. De Sutter Al, De Meyere MJ, Christiaens TC, Van Driel ML, Peersman W, De Maeseneer JM. Does amoxicillin improve outcomes in patients with purulent rhinorrhea? A pragmatic randomized double-blind controlled trial in family practice. J Fam Pract. 2002; 51(4):317-323.

26. Standing Medical Advisory Committee Sub-Group on Anti-Microbial Resistance. The path of least resistance. http://www.dh.gov.uk/ en/Publicationsandstatistics/Publications/PublicationsPolicyAndGuidance/DH_4009357. Accessed Dec 10, 2007.

27. Johnson JR. Principles of judicious antibiotic use: nonspecific upper respiratory tract infections. Ann Intern Med. 2002;136(9):709.

28. O'Brien K, Dowell SF, Schwartz B, et al. Cough illness/bronchitis-principles of judicious use of antimicrobial agents. Pediatrics. 1998;101(Suppl):178-181.

29. Rosenstein N, Phillips WR, Gerber MA, et al. The common cold-principles of judicious use of antimicrobial agents. Pediatrics. 1998; 101(Suppl):181-184.

30. Bourke A, Dattani H, Robinson M. Feasibility study and methodology to create a quality-evaluated database of primary care data. Inform Prim Care. 2004;12(3):171-177.

31. Hubbard R, Lewis S, Smith C, et al. Use of nicotine replacement therapy and the risk of acute myocardial infarction, stroke, and death. Tob Control. 2005;14(6):416-421.

32. Hubbard R, Lewis S, West J, et al. Bupropion and the risk of sudden death: a self-controlled case-series analysis using The Health Improvement Network. Thorax. 2005;60(10):848-850.

33. Nebeker JR, Hurdle JF, Bair BD. Future history: medical informatics in geriatrics. J Gerontol A Biol Sci Med Sci. 2003;58(9):M820-M825.

34. GPRD. Excellence in Public Health Research: Facts and Figures. http://www.gprd.com/whygprd/factsandfigures.asp. Accessed Mar 17, 2006

35. Margolis DJ, Bowe WP, Hoffstad O, Berlin JA. Antibiotic treatment of acne may be associated with upper respiratory tract infections. Arch Dermatol. 2005;141(9):1132-1136.

36. Gelfand J, Margolis DJ, Dattani H. The UK General Practice Research Database. In: Strom BL, ed. Pharmacoepidemiology. Chichester: John Wiley \& Sons, Ltd; 2005:337-346.

37. Meropol SB, Chan KA, Chen Z, et al. Adverse events associated with prolonged antibiotic use. Pharmacoepidemiol Drug Saf. 2008;17(5):523-532. Published Onlinejanuary242008. 
38. Meropol SB, Metlay JP. Validating pneumonia hospitalizations in the THIN Database. Abstracts of the 26th International Conference on Pharmacoepidemiology \& Therapeutic Risk Management. Brighton, UK. Pharmacoepidemiol Drug Saf. 2010;19(Suppl 1):S1-S347.

39. Meropol SB, Metlay JP, Localio AR. Accuracy of pneumonia hospital admissions in an ambulatory care electronic medical record database. Pharmacoepidemiol Drug Saf. 2012;21(6):659-665.

40. Flockhart D. Drug interactions: Cytochrome P450 Drug Interaction Table. http://medicine.iupui.edu/clinpharm/ddis/table.aspx. Accessed Jun 27, 2008

41. Woosley R, Anthony M, Armstrong EP, et al. QT Drug Lists by Risk Groups. http://www.azcert.org/medical-pros/drug-lists/bycategory. cfm\#. Accessed Jun 27, 2008.

42. Pai MP, Momary KM, Rodvold KA. Antibiotic drug interactions. Med Clin North Am. 2006;90(6):1223-1255.

43. Delanty N, Vaughan CJ, French JA. Medical causes of seizures. Lancet. 1998;352(9125):383-390.

44. Zeltser D, Justo D, Halkin A, Prokhorov V, Heller K, Viskin S. Torsade de pointes due to noncardiac drugs: most patients have easily identifiable risk factors. Medicine (Baltimore). 2003;82(4):282-290.

45. Schneeweiss S, Wang PS, Avorn J, Maclure M, Levin R, Glynn RJ Consistency of performance ranking of comorbidity adjustment scores in Canadian and U.S. utilization data. J Gen Intern Med. 2004;19(5 Pt 1):444-450.

46. Townsend deprivation index. Geographical Referencing Learning Resources. http://www.geog.soton.ac.uk/geo-refer/go3_142_ c15p19819999snsw.html. Accessed Apr 22, 2012.

47. Get SMART. Know When Antibiotics Work, US Centers for Disease Control and Prevention, US Department of Human Services. http:// www.cdc.gov/getsmart/.

48. Akaike H. A new look at the statistical model identification. IKEEE Transactions on Automatic Control. 1974;AC-19(6):716-723.

49. Cuzick J. A Wilcoxon-type test for trend. Stat Med. 1985;4(1):87-90.

50. Metlay JP, Shea JA, Crossette LB, Asch DA. Tensions in antibiotic prescribing: pitting social concerns against the interests of individual patients. J Gen Intern Med. 2002;17(2):87-94.
51. Majeed A, Williams S, Jarman B, Aylin P. Prescribing of antibiotics and admissions for respiratory tract infections in England. BMJ. 2004;329(7471):879.

52. Mainous AG III, Saxena S, Hueston WJ, Everett CJ, Majeed A. Ambulatory antibiotic prescribing for acute bronchitis and cough and hospital admissions for respiratory infections: time trends analysis. J R Soc Med. 2006;99(7):358-362.

53. Petersen I, Johnson AM, Islam A, Duckworth G, Livermore DM, Hayward AC. Protective effect of antibiotics against serious complications of common respiratory tract infections: retrospective cohort study with the UK General Practice Research Database. BMJ. 2007;335(7627):982.

54. Hollowell J. The General Practice Research Database: quality of morbidity data. Popul Trends. 1997;(87):36-40.

55. Hall G, Luscombe DK, Walker SR. Post-marketing surveillance using a computerised general practice database. Pharmaceutical Medicine. 1988;2:345-351.

56. Gafter-Gvili A, Fraser A, Paul M, et al. Antibiotic prophylaxis for bacterial infections in afebrile neutropenic patients following chemotherapy. Cochrane Database Syst Rev. 2012;1:CD004386.

57. Wenzel RP, Gennings C. Bloodstream infections due to Candida species in the intensive care unit: identifying especially highrisk patients to determine prevention strategies. Clin Infect Dis. 2005;41(Suppl 6):S389-S393.

58. Young J, De Sutter A, Merenstein D, et al. Antibiotics for adults with clinically diagnosed acute rhinosinusitis: a meta-analysis of individual patient data. Lancet. 2008;371(9616):908-914.

59. Meropol SB. Valuing reduced antibiotic use for pediatric acute otitis media. Pediatrics. 2008;121(4):669-673.

60. Laxminarayan R, Malani A, Howard D, Smith DL. Extending the Cure: Policy responses to the growing threat of antibiotic resistance. http://www.extendingthecure.org/sites/default/files/ETC_FULL.pdf. Accessed Mar 2007.

61. Cals JW, Schot MJ, de Jong SA, Dinant GJ, Hopstaken RM. Point-ofcare C-reactive protein testing and antibiotic prescribing for respiratory tract infections: a randomized controlled trial. Ann Fam Med. 2010;8(2):124-133. 